\title{
Miami Rising: Historical Perspectives on Sea Level Rise as a View into the Future
}

\author{
Eric Firley, Victor Deupi
}

\begin{abstract}
Miami is a city whose diversity and vibrant growth has made it an ideal destination for international travel, business, and leisure. However, South Florida is a hurricane prone region, and the threat of sea level rise and erosion poses an immediate and long-term risk to the stability of the city and its region. The city and the scientific community have been studying the phenomenon for some time now, proposing solutions to the management of such threatening uncertainty. Yet the quest for coastal resilience is not a new phenomenon. Since ancient times human settlements have entertained a complex relationship to the water. This paper will explore how several cities throughout history have dealt with flood resilience challenges and consider how historical attempts to adapt and address such problems can provide new spatial strategies for Miami's future. Aware of the fact that such a study cannot reveal technical solutions for the twenty-first century, the emphasis will be given to an understanding of the correlation between socio-economic identity, attitude towards defensive action, and the type of organization needed for concerted action.
\end{abstract}

Keywords: coastal resilience, flooding, history, Miami-Dade County, sea level rise

Miami-Dade County features on the list of the world's most vulnerable regions to the effects of sea level rise. With variations according to the type and origin of the forecast model, the southern tip of the Floridian peninsula will have to cope over the next fortyfive years with up to $3 \mathrm{ft}$. [0,9 $\mathrm{m}]$ higher water levels than today. ${ }^{1}$ Without human intervention, this trend would 
transform the lowest laying landmasses, with Miami Beach as the most prominent example, into almost fully covered watersheds. ${ }^{2}$ The complexity of previsionary planning is raised by the fact that the region is also prone to hurricane disasters. Depending on the strength of the coming storms, the combined effect and impact on city life can hence vary considerably.

While these conditions might be typical for the majority of flood-endangered places throughout the world, the Florida Peninsula has in addition the geological particularity of porous ground. It rests on a vast plateau of karst limestone with significant areas of dissolved rock, underground drainage, and numerous abrupt ridges, fissures, sink-holes, and caverns. As a consequence, traditional flood control methods such as structural levees, floodways, channel improvement, and reservoirs may not be suitable solutions as water can still travel through the bedrock and rise wherever necessary. For this reason, and its consequences for flora, fauna, building foundations, drink water provision and the highly vulnerable ecosystem of the neighboring Everglades, Miami and the greater South Florida region, has been described as the ground-zero for sea level rise inquiry and discourse. A result of this preoccupying situation is the fact that the topic of sea level rise has gradually escaped the domain of "experts-only" discussions, inviting the professional community and wider public to reflect about the city's coming fate. A milestone has recently been reached, when an insurance company refused to pay for flood damages that occurred in the ground floor of a commercial building on South Beach. ${ }^{3}$ According to the insurance company, the city's gradual elevation of the street level had transformed the ground level into a legal basement, for which the owner's policy had no validity. Examples like this one will multiply in the near future, forcing the local community and the public sector to react and take a position.

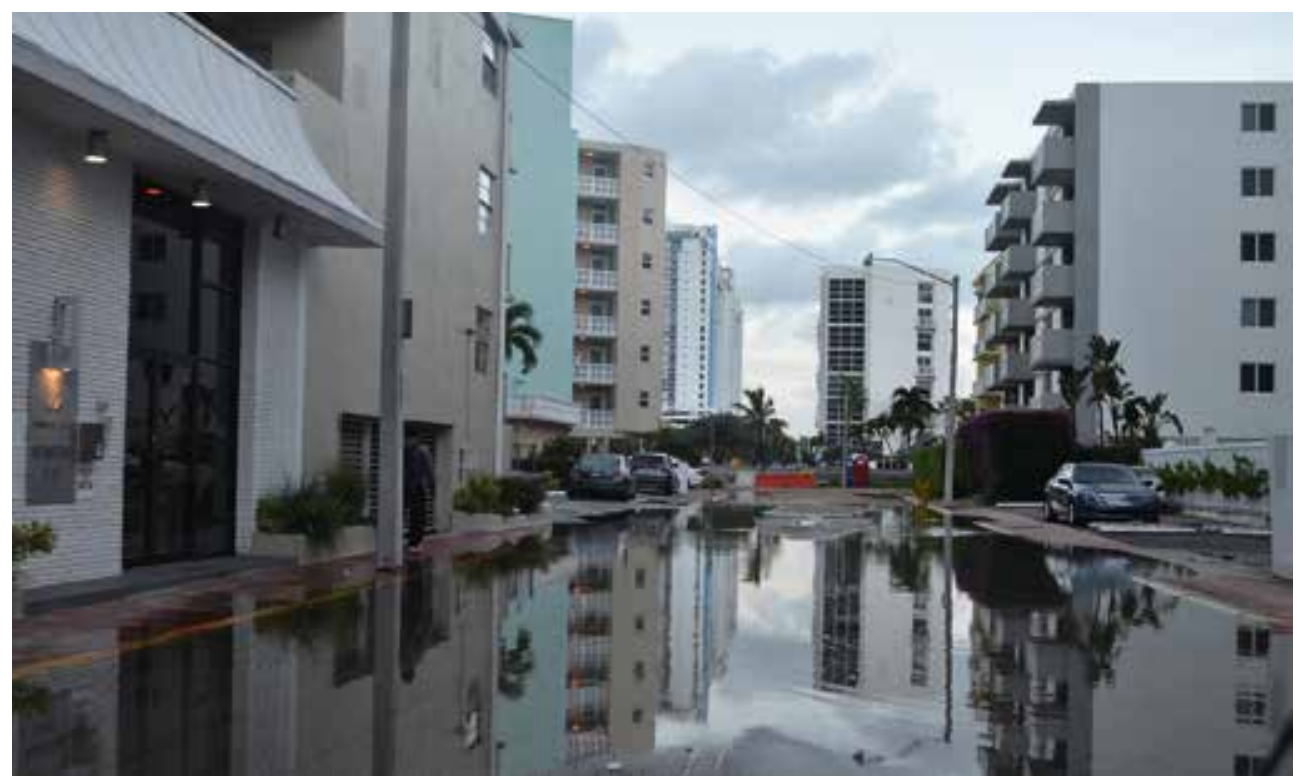

Figure 1. A street in Miami Beach during king tide, October 12, 2016. 
Yet while we wait for the scientists to identify possible structural solutions to managing the threat of sea level rise, this paper "leaps back" in history (which is the literal meaning of the Latin term resilire) in order to situate these water and flood related issues in a societal and political - rather than technical - context. It is an alternative position on the topic that complements the quest for the most efficient engineering solution for coastal protection and stability, wondering if the selection of such measures is not more culturally driven than one might expect. Short- and middle-term political, personal and economic interests have a tendency to obstruct the long-term view, particularly in a young city like Miami in which the threat of flooding constitutes a novelty. The authors therefore decided to gather material about settlements that have a far more entrenched relationship to recurring inundations. They try to understand what the flooding challenge meant for the development of the local identity and how it varied according to regional particularities during specific moments in time. Due to this societal focus, the selection of case studies is not primarily based on geographic and geological similarities between Miami and the historic precedents.

In this context of conceptual comparison, it is worthwhile mentioning that the alleged uniqueness of the contemporary version of sea level rise in the form of a continuously worsening trend is debatable. Earlier phenomena might not have been based on a global event such as the melting of ice caps, but subjectively they must have appeared to the local community in a similar light. Just like us today, these communities witnessed recurring and often intensifying inundations, and tried to agree on measures on how to prevent or limit their undesirable effects. Our contribution underlines the idea that history cannot teach us - that these case studies cannot reveal technical solutions for the twenty-first century - but that we

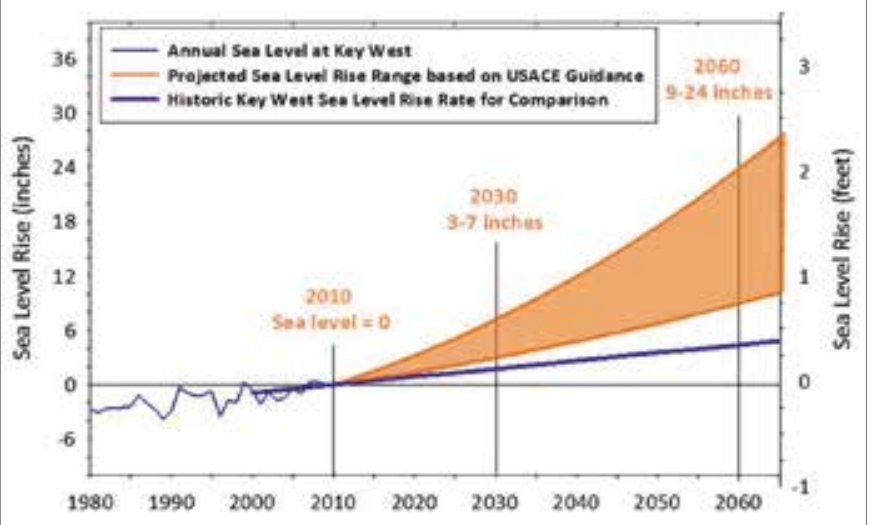

Figure 2. Sea level rise forecasts provided by the United States Army Corps of Engineers, 2009.

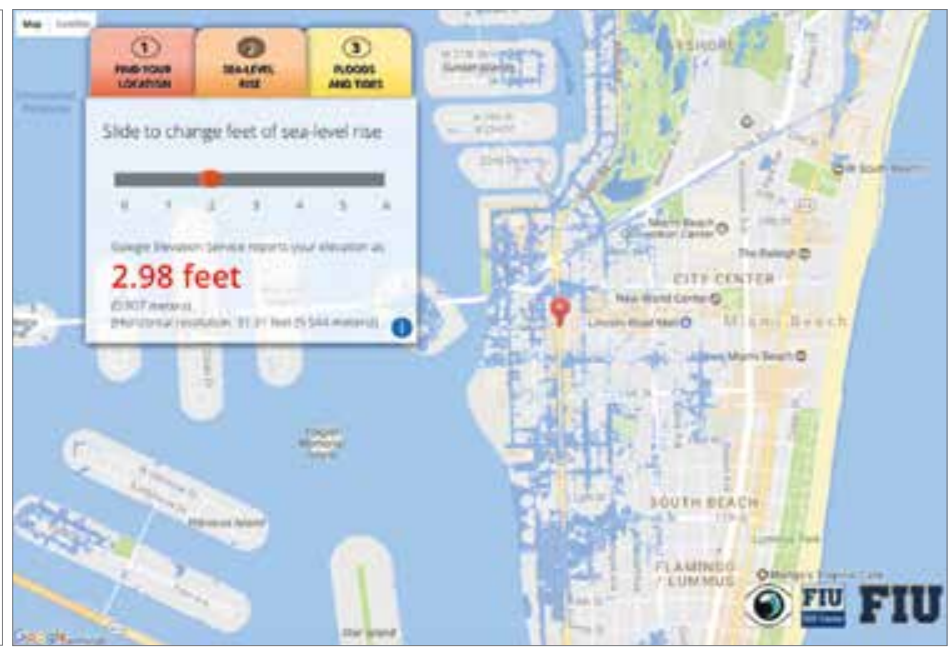

Figure 3. Visualization of South Beach in the event of a $2 \mathrm{ft}$. [61 cm] increase of the sea level, www.eyesontherise.org. 
can learn from them. By studying these precedents, we can develop a better understanding of the correlation between socio-economic identity, attitude towards defensive action, and the type of organization needed for concerted action.

\section{RESEARCH}

On the following pages, the authors will summarize case studies of Ancient Rome, Venice, New Orleans, and Sacramento, and explain in what ways these historic snapshots are relevant to the present situation in Miami. The case studies will consider both the resistance and adaption to sea level rise, flooding, and other water-related disturbances that characterized each place. Taking into account how ecologists view resilience, and in particular C.S. Hollings definition of it as a measure of a system's ability to absorb change and persist after a perturbation, the authors will focus on the ongoing response of these settlements to floods. ${ }^{4}$ While in many instances flood resistance is simply re-building after a destructive event, the authors will seek to understand what adjustments took place in the rebuilding and how these conditions shaped people's perceptions.

\section{Ancient Rome}

From the very beginning, Rome was mythically associated with the flooding of the city. ${ }^{5}$ As noted by Gregory Aldrete in Floods of the Tiber in Ancient Rome, the well-known legend of Romulus and Remus rescued by the she-wolf sidesteps the key point that King Amulius had ordered the twins to be placed in a basket and thrown into the Tiber River. The basket washed ashore as the man charged with drowning the boys could not get far enough into the river to release them into the torrent. The Tiber had flooded due to winter rains, and standing pools of water prevented the basket from catching a current and taking the boys down river, if not out to sea. Therefore, the twin sons of Rhea Silvia, who had been raped by Mars, were rescued by the wolf and subsequently raised by a shepherd. Eventually the twins decided to found a new city on the very spot where the wolf had discovered them. But as luck would have it, fratricide ensued when the two could not agree as to who should give their name to the city. Romulus won out and became its first king.

The legend of Romulus and Remus underlines the complicated relationship Rome has always had with the flood-prone Tiber. The river that ironically saved the founder's life would also frequently savage the city through relentless floods and other water-related destruction. Clearly, the city's location was poorly chosen, a problem that continues to plague cities throughout the world today. A large part of it was situated on land that was inherently marshy and on a point of the Tiber River that was prone to severe flooding, a fact that goes against any common sense planning. As noted by Aldrete, written descriptions of floods in ancient Rome 
suggest that between $414 \mathrm{BCE}$ and $398 \mathrm{CE}$, there were thirty-three years of significant flooding. ${ }^{6}$ Of course, this does not take into account regular flooding due to excessive rainfall, or flash floods caused by thunderstorms. Nevertheless, there is no known author who intentionally wrote an account of floods in ancient Rome, or a comprehensive history of floods in the Roman world. Not even the ancient Roman architect, engineer, and writer Vitruvius, whose treatise De architectura (On Architecture) appeared in the second half of the first century BCE, mentioned flooding or the associated flood-related damages to buildings. ${ }^{7}$ Therefore, when considering the effects of floods on Ancient Rome, we have to take into account more general conditions, both mythical and practical.

Vitruvius' treatise was the only comprehensive text on architectural theory and practice to have survived from Classical antiquity, though he never dealt specifically with floods or flooding. Yet from the beginning of the treatise - at the end of Book I - he describes the proper way to lay out a healthy, idealized city, based on hygiene, meteorology, the regime of the winds, and the light and heat of the sun, a proposal that clearly side skirts Ancient Rome. He warns of building in swampy, marsh-like places and the associated health risks that come from living in such environments.

Those places [...] which have stagnant marshes, and lack flowing outlets, whether rivers or by dykes, like the Pomptine (sic) marshes, by standing become foul and send forth heavy and pestilent moisture. ${ }^{8}$

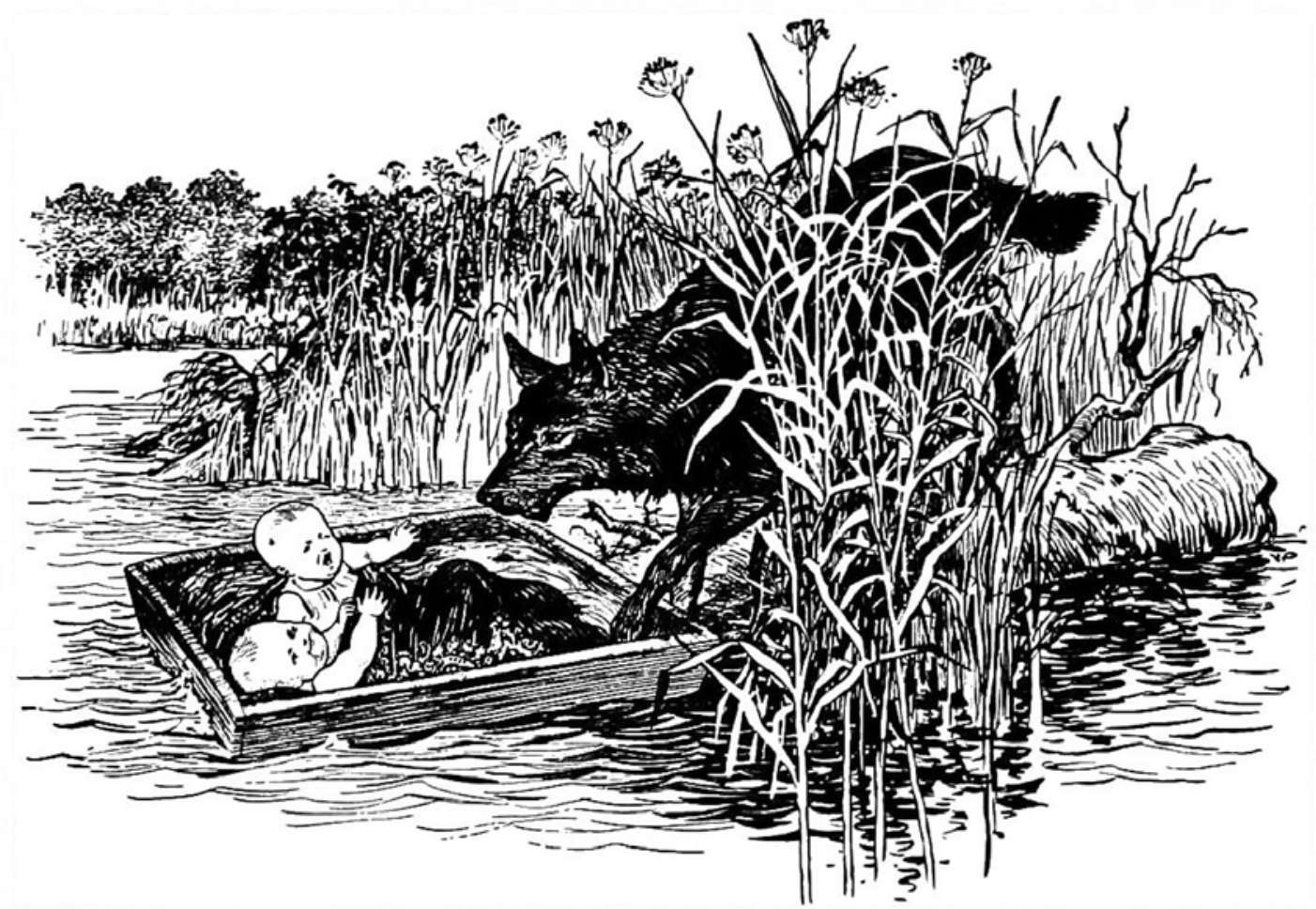

Figure 4. Romulus and Remus rescued by a she-wolf during a flood event. 
Elsewhere in Book II, he warns of poorly made masonry walls and improperly mixed Roman mortar, careless constructional techniques that when exposed to water and continuous moisture, can result in the loss of structural integrity or collapse. More importantly, he dedicated Book VIII entirely to hydrology and hydraulics. In it, he discusses the ways of locating good water, and the building of aqueducts, wells, and cisterns. Finally, in Book IX he treats of water clocks and organs, largely in relation to ancient mathematics. He even provides the oldest surviving account of Archimedes' discovery of the relative weight between gold and silver in the fraudulent case of the gold crown - a discovery that could not have been made without the use of water.

So what is one to make of all of this? Ancient Rome was clearly founded on sacred soil, however swampy the low-lying valleys between the seven hills may have been. However, the legend of Romulus and Remus succeeded the city's foundation by several centuries, and therefore provided a divine and retrospective explanation for the damages resulting from seasonal inundations. The fact that Vitruvius never explicitly mentioned the flooding issue suggests that he took it for granted or fatalistically accepted is as a force majeure. His omission also suggests that the consequences may have rarely been disastrous, leading one to believe that for Vitruvius, these kinds of random acts of nature may have been beyond one's ability to resist, let alone foresee.

It is generally accepted that the earliest (and wealthiest) inhabitants of Rome occupied the elevated sectors of the city, and that the low-lying regions contained streams and lakes that regularly flooded during rainy seasons. As the city grew and expanded, it had to adopt engineering/ resistant responses to flooding in order to accommodate the new lowlying urban districts. This resulted in the construction of elevated ground levels and fill projects, an engineered drain (Cloaca Maxima) system and canals, and the building of floodwalls, embankments, and earthen levees. Yet despite these extensive flood control efforts, the city continued to suffer from inundations and the Roman people had to live with the floodprone nature of their city, adapting their lifestyles and building practices to accommodate the seemingly random acts of nature. Aldrete traces Ancient Rome's surprising resiliency back to five major parameters: the widespread existence of hills as a refuge, the flood-resistance of the major public buildings through over-engineered foundations and an appropriate choice of materials, the housing patterns with the elites residing on protected hilltops, the relative security of the food storages, and the continuing provision of drinking water coming from the nearby mountains.

These points, including the mentality to comprehend natural disasters as fatal incidences, could be included in a matrix helping us to evaluate flood resiliency for twenty-first century Miami. However, it is important to 


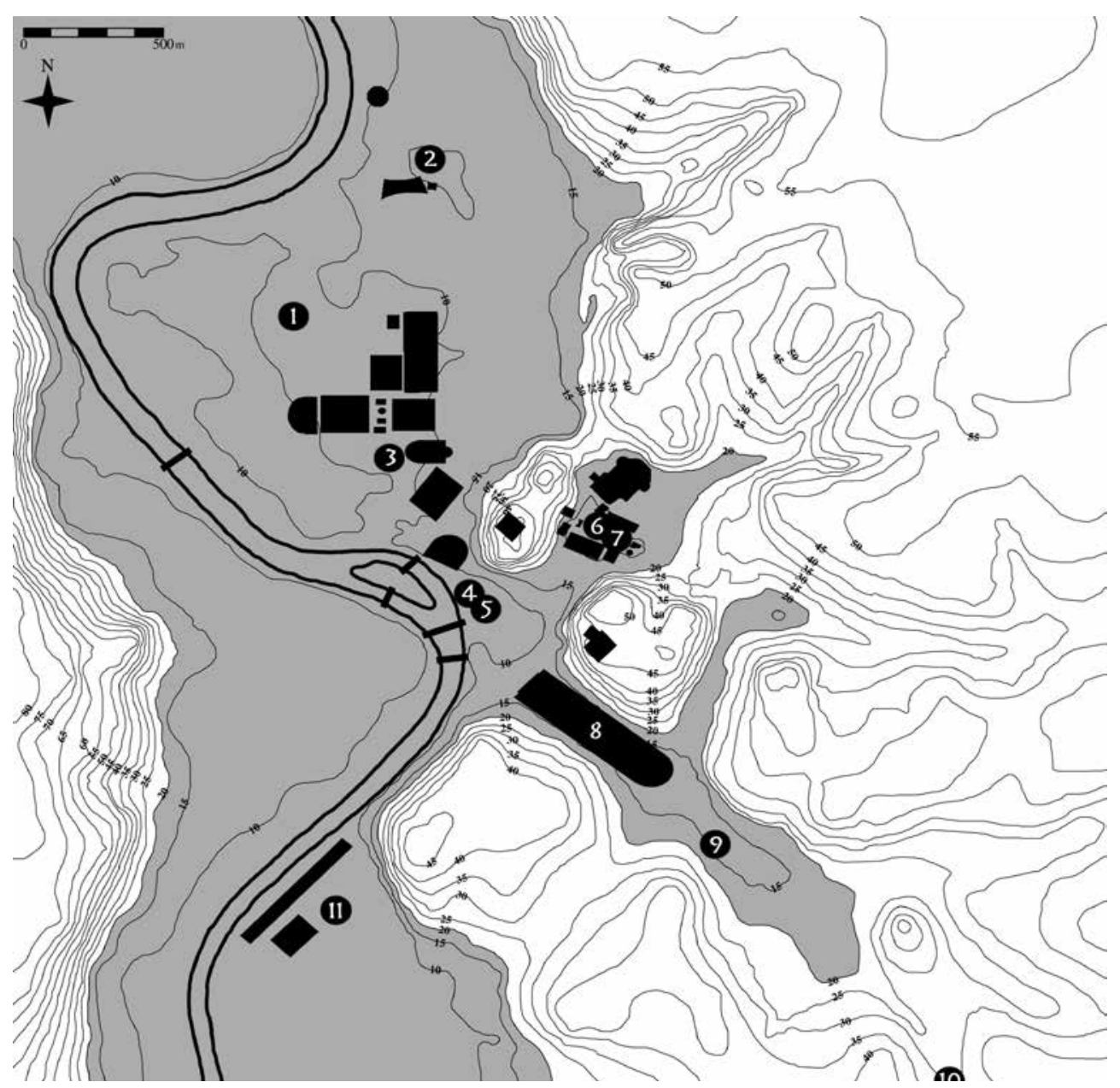

Figure 5. This map shows the situation of the major public buildings within the catchment zone of an extraordinary flood in Ancient Rome.

remember that in the case of Ancient Rome, the topography of its location allowed building to occur on higher ground, and the hills to provide an uninterrupted supply of clean water (a happy coincidence). Miami is not as fortunate as it was built on largely flat (and porous) land and any efforts to introduce higher ground in the future will be met with significant structural and environmental challenges. Nevertheless, Vitruvius' description of foundation design and material choice for buildings within the flood zone, may be seen as a direct response to conditions of inundation - a resilient approach since the disruption (i.e., flooding) is incorporated into the system, rather than excluded from it. Miami may have to think in such Vitruvian terms should it ever consider elevating the city as a means to live with the persistent threat of sea-level rise and erosion.

\section{Venice}

Venice is an extreme example of the intrinsic paradox that is characteristic for the foundation of many cities, particularly in Europe, because the 
defensive military protection provided by special geographic features usually goes hand in hand with constraints in other fields than the defensive one. In the case of Venice, it was the secluded location within a natural lagoon that favored its survival during the barbaric invasions of Italy. ${ }^{9}$ The city developed, when others, situated on the mainland, struggled or perished. However, the downside of the efficient natural protection was the constant threat of seasonal flooding, the need to clear the lagoon from sedimentation along the shipping channels, and the establishment of a building culture that necessitated the fairly costly use of foundations that were made out of a myriad of wooden piles. Hence, the "water-impregnated" culture that these starting conditions helped to shape is as unique as the city's stupendous physical reality.

As described by Karl Appuhn in his study of late seventeenth century water-management innovations in Venice, the city fathers had historically regarded their natural environment in a surprisingly conservationist manner. ${ }^{10}$ Though forced since the thirteenth century to intervene constantly in river diversions, dredging and breakwater construction, the city leaders were reluctant to drain and reclaim its shallow surroundings and to alter the shape of the lagoon. This position remained enforced long after the existence of defensive measures had become redundant. "The lagoon lay at the very heart of some of the most fiercely contested political debates in Venetian history." 11 These debates transcended purely economic considerations, and achieved a symbolic dimension in equating the lagoon and its conservation as a wetland with the population's selfunderstanding as a maritime people. Reclaiming the marshy periphery, in contrast, would have symbolized an increasing orientation towards the mainland, and agricultural rather than commercial activities. Another, even more explicitly political reason for the conservationist attitude towards the water was the city-state's status as a republic: "For most of Venice's ruling class the public good [...] was synonymous with preserving the lagoon as a large wetland rather than draining it and transforming it into arable land as was being done in other parts of Europe." ${ }^{12}$ These convictions also had an engineering impact, and explain why Venice's water management innovations were - despite the city's impressive international reach and high level of education - developed only internally, on the base of a fairly "vernacular science" of trial and error. It was feared that the application of foreign technological innovations would open the door for a reversal of the above-mentioned public principle. As shows the example given by Appuhn, such reproach was eventually made to the Dutch levee construction technology that - in its country of origin - usually went along with large-scale reclamation projects that were implemented by the private sector. Next to the political and economic agenda, there was also an environmental one: "The lagoon was understood to be a delicate structure in need of constant care [...] and the Venetians were its divinely appointed caretakers." 13 
This episode, describing the city council's refusal to apply the most advanced technologies in levee construction and to continue relying on traditional techniques until the very end of the eighteenth century, has been chosen, because it showcases how complex and seemingly random the relationship between a technical solution and a practical need can be. At first glance, one could present this dismissive attitude towards technical progress as a simple mistake and sign of backwardness, but longer consideration offers an alternative interpretation and questions the cultural neutrality of technological innovation. It was not solely because of provincialism and protectionism that the Venetian city leaders reacted suspiciously to the introduction of a new and allegedly advanced levee technology for breakwater reinforcement. They knew that this technology was usually applied in a context of land reclamation, a practice that went against their cultural and political beliefs. These figurative and symbolic objections were followed by physical and empirical ones, after the underfunded and repeatedly deferred trial installation of the new levees underperformed. This unfortunate outcome seems to have been caused by a faulty implementation that lacked the permeability of both the Venetian-style, but also the original Dutch-style design: as a result, the levee acted as a wall, and succumbed to the pressure of the raising water.

In the context of this paper, these findings reveal two points: the political and cultural dimension of a specific natural setting and traditional way of doing things, and the technical difficulty of displacing remediation measures from one ecosystem to another. For Miami in particular, the question arises as how deeply its identity is rooted in an image provided by the natural setting, dominated by Ocean Drive and beaches that stretch over the entire eastern shore of Miami Beach. It is this setting, and the one of the whole Biscayne Bay, that is most endangered by the rising sea levels. If the Venice government refused to conduct measures that questioned - and this only symbolically - its orientation towards the sea, would Miami hesitate to conduct measures that could negatively impact some of its most famous postcard views? In both cases, this is not only a question of myth preservation, but also one of economic rationale and marketing allure. Unlike Venice, Miami's myth is not based on a predominantly cultural, historic and architectural view of the city. But is it really just about party, money and the beach, as critics tend to repeat? From the cities discussed in this paper, the two are today the ones that most rely on tourism and secondary homeowners. For Venice, this has been a long historic development. For Miami, it has always been the case, but the city hardly counts more than a century of existence. Arguably, sea level rise will help Miami and its residents to better identify on what myth it is built upon. How much adaptation, may it be physical, social or economic, will it be able to digest? How resilient is the myth to change and adaptation? 


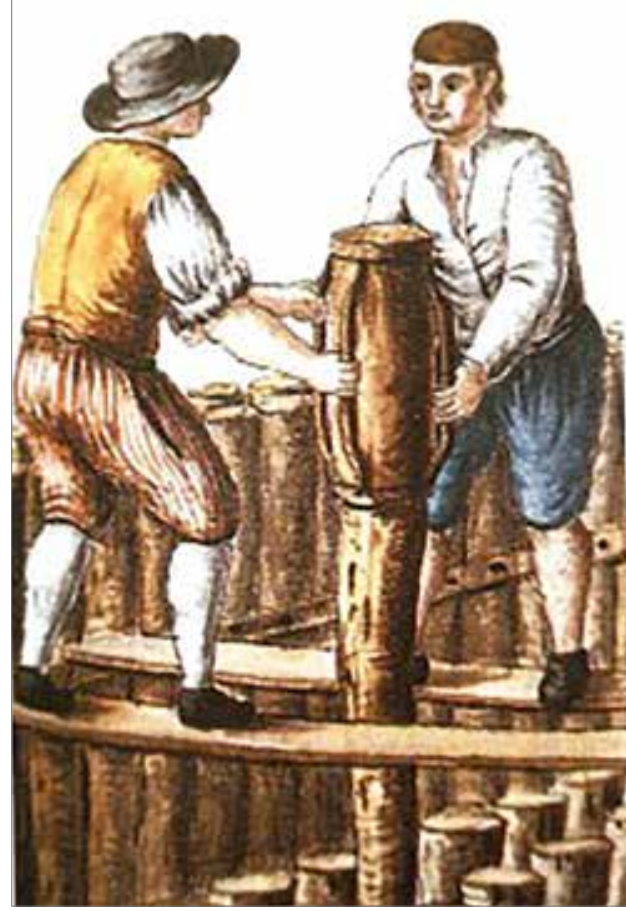

Figure 6. Eighteenth century pile drivers working on the foundations for a Venetian church.

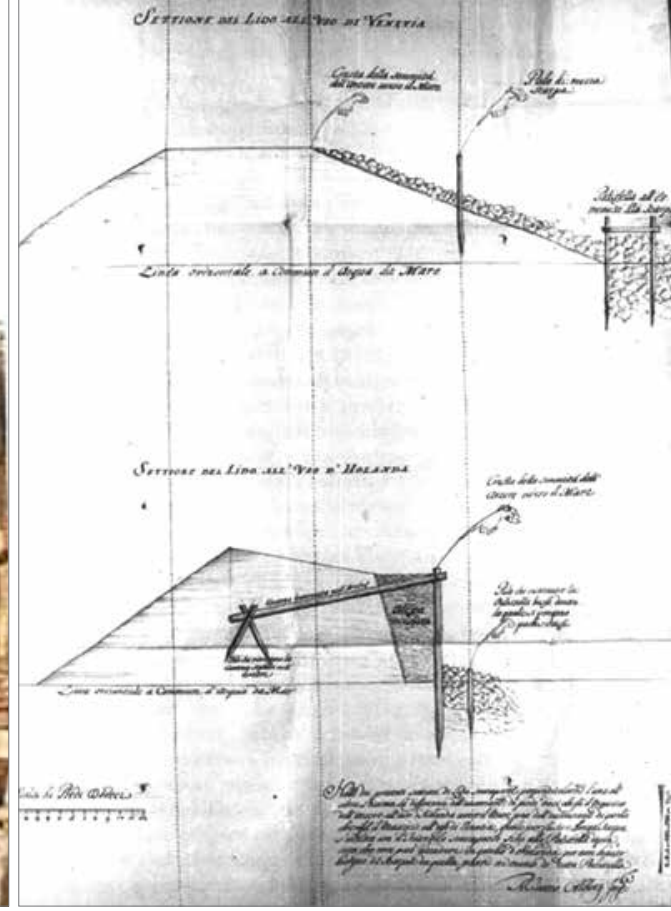

Figure 7. A comparison of levee design between the Netherlands (bottom) and Venice in the late seventeenth century.

\section{New Orleans}

From the very beginning of its colonization in the first decade of the eighteenth century, the city of New Orleans had to adapt to destructive river flooding, hurricane storm surge, and high sea level rise. ${ }^{14}$ Given its strategic location along the east bank of the Mississippi River, the earliest settlement was situated along the natural levees of the river approximately $10 \mathrm{ft}$. [3 m] above sea level. The earliest settlers understood the value and common sense of building on high ground, and in 1719 constructed a 3 $\mathrm{ft}$. $[0,9 \mathrm{~m}]$ high levee along the existing bank to protect further from river and tidal overflow. In 1721, French engineers produced a new city plan, the Vieux Carré, or French Quarter as it is called today, that consisted of a rectangular grid of streets and blocks that met at right angles, with a perimeter wall and canal that emptied into Lake Pontchartrain nearby. New Orleans' first recorded hurricane struck the brand new capital the following year, in 1722, causing the widespread destruction of homes, public buildings, and ships docked in the harbor. The city's baptism by fire was a cruel prelude to what would become a regular pattern of particularly painful natural disasters.

The Spanish occupation of New Orleans (1764-1803) coincided with the development of other Spanish cities in the Caribbean and Gulf of Mexico such as Havana, Santiago de Cuba, Santo Domingo, and Cartagena de las 
Indias. ${ }^{15}$ Like New Orleans, these Spanish settlements were all "cursed by nature" if not "the will of God," as they regularly alternated between periods of drought and deluge. In an effort to survive with the elements, the Spanish introduced new resistant methods of construction to protect buildings from fire or flooding, improved sewer and storm water drainage, and in the case of New Orleans, built a new canal to facilitate the transportation of goods from Lake Pontchartrain to the city proper. All of these engineering strategies sought to optimize the city's already delicate relationship between safety and economic expansion. Despite the increased living standards brought about by the Spanish, hurricanes and tropical storms continued to batter New Orleans in 1776, 1779 (twice), 1780, 1781, 1793, and $1794 .{ }^{16}$ The areas outside of the walls remained poorly drained, disease-ridden, and in constant danger of flooding. Yet the Spanish were firm in their colonial expansion into North America, and this may very well have contributed to their development of a strong psychological resilience to disaster. Their building practices also influenced the character of the French Quarter significantly, with taller and larger courtyard buildings becoming the norm. Fireproof slate-shingled roofs, metal balconies and railings, and masonry structures all contributed to a Spanish character that would endure and forever be associated with the French Quarter. This was the New Orleans that the United States acquired with the Louisiana Purchase of 1803.

In the early nineteenth century, the city witnessed an extended period of economic, industrial, and population growth, and as a result expanded outwards along the river and to the north towards Lake Pontchartrain. At best, the new districts were built prudently along the levees of the

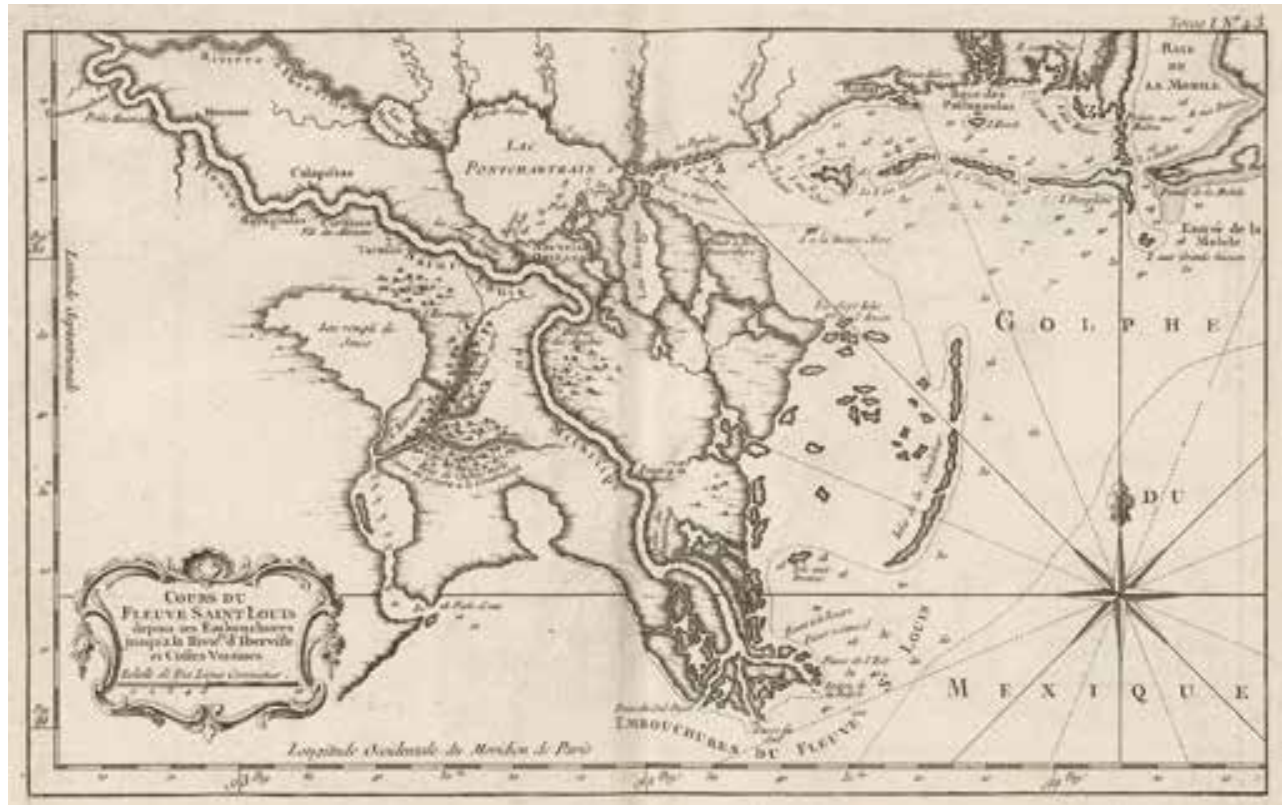

Figure 8. Map of the New Orleans region dated 1764. 
river, but in the case of the areas north of the city, new districts were carelessly developed on land that Vitruvius would have declared unsuitable for building. Elevated wooden homes became the standard form of construction in these poorly-chosen, low-lying districts. And, like the French and Spanish before them, the Americans had to cope with continuous hurricanes and tropical storms - at least one per decade throughout the nineteenth century - that caused widespread flooding and large-scale destruction. After the Civil War (1861-1865) ended, military engineers put in place new sanitary measures to improve drainage and water control, largely to improve public health rather than protect against damaging floods or storms. As the city continued to expand in the latter half of the nineteenth century, new canals were constructed to connect the new districts with Lake Pontchartrain. Yet these new residential areas were built on low-lying land, at approximately sea level rather than along the elevated levees of the river. The century ended tragically with the Hurricane of 1893 resulting in the greatest loss of life the city ever witnessed, over 2,000 fatalities and massive flooding.

In the early twentieth century, the city developed comprehensive zoning, transportation infrastructure, improved drainage and levee systems, and increased the construction of elevated houses. As the city improved its construction standards, many existing buildings were subsequently elevated or moved. Yet, the city continued to expand toward the banks of Lake Pontchartrain on shallow, formerly swampy ground. Post World War II construction brought about the end of elevated houses and introduced the concrete slab-construction that was popular throughout the United States. The city's faith in improved technology and the acceptance of commercially driven residential construction resulted in the ultimate test when Hurricane Katrina ravaged New Orleans and the Mississippi Gulf Coast on August 29, 2005. Though the hurricane did not strike the city directly, the storm surge associated with it breached the levees of Lake Pontchartrain, catastrophically destroying the low-lying areas of the city and causing nearly 2,000 fatalities. The wealthier, older neighborhoods along the river suffered little damage and the levees along the Mississippi river were never breached. Nearly three hundred years after the city's founding, the residents of New Orleans are more than ever determined to continue living in a place that has seen continuous water-related damage and destruction with little hope that future storms and floods will go away.

This famous case study documents particularly well some of the most obvious points influencing flood resiliency: the appropriateness of construction types and of geographic location. And for both of these parameters, contemporary Miami does not score much better than New Orleans. The vernacular building tradition has been largely lost and low-lying areas have been densely developed. A significant difference from Ancient Rome or New Orleans is the fact that social segregation in Miami does not always correlate with elevation. There are of course higher areas 
(Coconut Grove and Coral Gables) where the wealthier neighborhoods were first built, but this is no longer the recurring pattern. This condition might be linked to the historically less frequent occurrence of floods, the coastal location and the legacy as a seasonal tourist destination. Arguably, this can be interpreted as an opportunity, and might convince the elites to take swift action. Pessimists could claim the opposite.

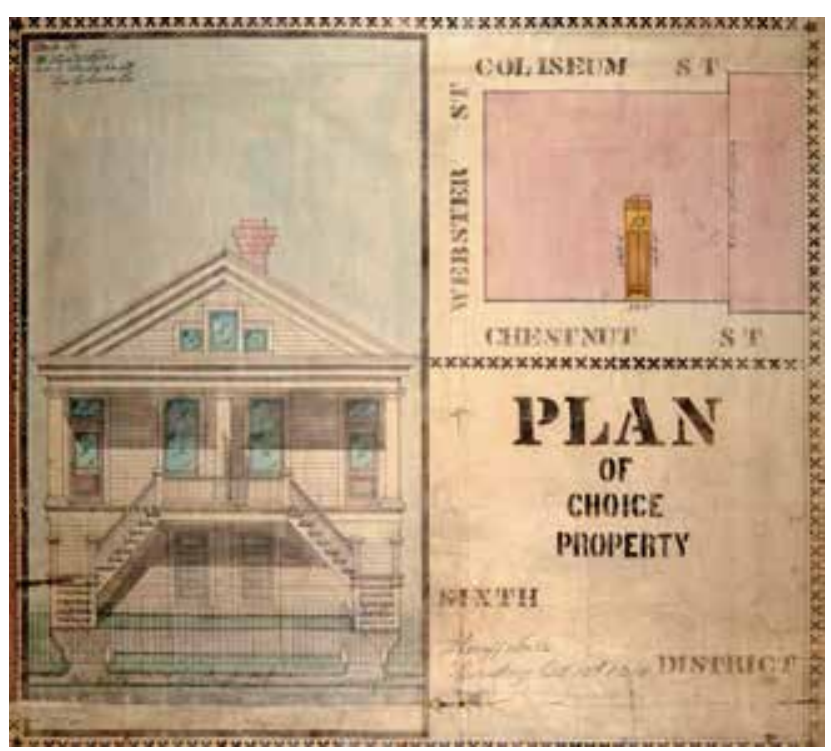

Figure 9. Plan for a raised basement house in New Orleans, 1913.

\section{Sacramento}

The development of Sacramento is closely linked to the California gold rush that started in the late 1840s. The city, situated at the juncture of the American and the Sacramento rivers, managed to establish itself as a major point of distribution and commerce between San Francisco and the coast, on the one side, and the mines of the gold country, on the other. Merchants and miners first came by boat and after termination of the Sacramento Valley Railroad in 1856 also by train. The gold rush's tempting promise of quick gains led to remarkable population spikes: between October 1849 and the early summer 1850, the size more than tripled from 2000 to over 7000 inhabitants. This prosperous fate was however not shared by all similar real-estate ventures, a failing example being provided by the city of Vernon that vanished already four years after its foundation in 1849. The reason for this fiasco was not only the settlement's direct competition with Sacramento, and later Yuba, but also its even higher vulnerability to seasonal flooding. ${ }^{17}$ New Helvetia, situated just two miles south of Sacramento along the Sacramento river, suffered a similar downfall, ironically linked to the fact that it had been founded with the intent to engage in agriculture rather than mining. Once the rumors of gold discovery had spread, the project of Swiss-Mexican impresario Johann Sutter fell apart. 
Sacramento - and some other new cities like Marysville and Stockton prevailed and flourished, but the flooding issue turned out to be far more serious than anyone expected. Indigenous advice was not sought after, and it took the adventurous immigrants several years to understand that the first winter floods of 1849 and 1850 were not exceptional events, but typical seasonal occurrences in the Sacramento Valley, with more or less catastrophic outcomes. Due to the special conditions of the gold rush, the city nevertheless grew quickly. It entered a long phase of spontaneous and uncoordinated defensive action, mostly in the form of levee construction, even though a relocation to higher ground might have been an economically more reasonable solution. The detrimental effects gradually intensified through deforestation along the riverbanks and since the 1870s through hydraulic mining, filling the Sacramento River and its tributaries with vast amounts of sediment. In addition to the partly contradicting and often flood reinforcing levee construction measures, several dams were built at crevasses along the Sacramento and Feather rivers in order to help master the situation. The results were usually poor and led in some cases to armed confrontations between differently affected landowners. This early period, referred to as the "Levee-Wars Era," came to an end after two particularly severe flooding disasters in the years 1907 and 1909. ${ }^{18}$

Several earlier attempts for concerted and federally funded action were pushed forward and eventually culminated in a statewide flood control plan and one of the country's most complex infrastructural undertakings.

What is particularly interesting about this case study is the ability to document the socio-political effect of a major natural threat on an affected community's power structure and cohesion. These effects are far from obvious, as explained by Andrew C. Isenberg, who claims that Sacramento embarked on comparably efficient flood control projects "not because it had the brightest prospects, but ironically because its government [...] intuited that a flood control project might boost public support." ${ }^{19}$ The city had been founded in 1848 by Peter Burnett and the son of the abovementioned Johann Sutter, on grounds that were thought to belong to his father's land grant of 48,000 acres [19.425 ha], received in 1838 from the Mexican government. A closer look at the grant, taken by future squatters, however revealed that it excluded riverine land. This stipulation had not worried Sutter Sr., interested in agriculture, but it put into question the founding rights of a city that had been founded in a floodplain, directly along the riverbanks and at the juncture of two regularly overflowing rivers. This delicate legal situation was exacerbated by the fact that the city government was made up of major businessmen and speculators, people who had a fairly transparent interest in keeping the status quo in terms of landownership. It is in this context that flood control revealed its use not only as a physically protective measure, but also as a method to provide legitimacy to the established power and, at the same time, a way to evaluate its performance. 
One of the earliest examples was, in April 1850, the election to mayor of the merchant and speculator Hardin Bigelow, who had built - following the refusal of the city council - at his own expenses a levee that protected the city during the March inundations. His first action, approved by 543 against 15 votes, was to call a referendum that secured $\$ 250,000$ in taxes for the construction of additional protection..$^{20}$ This first sign of solidarity did not, however, solve the city's socio-political issues. Only four months later severe riots erupted and the state militia was sent in, after the California courts had decided against the squatters' claim for landownership. Bigelow himself was shot by squatters, and died of cholera during his recovery. Internal tensions continued for a long time to come, but flood control through increasingly sophisticated and expensive means seemed to have acted as a binding element for the local population. ${ }^{21}$

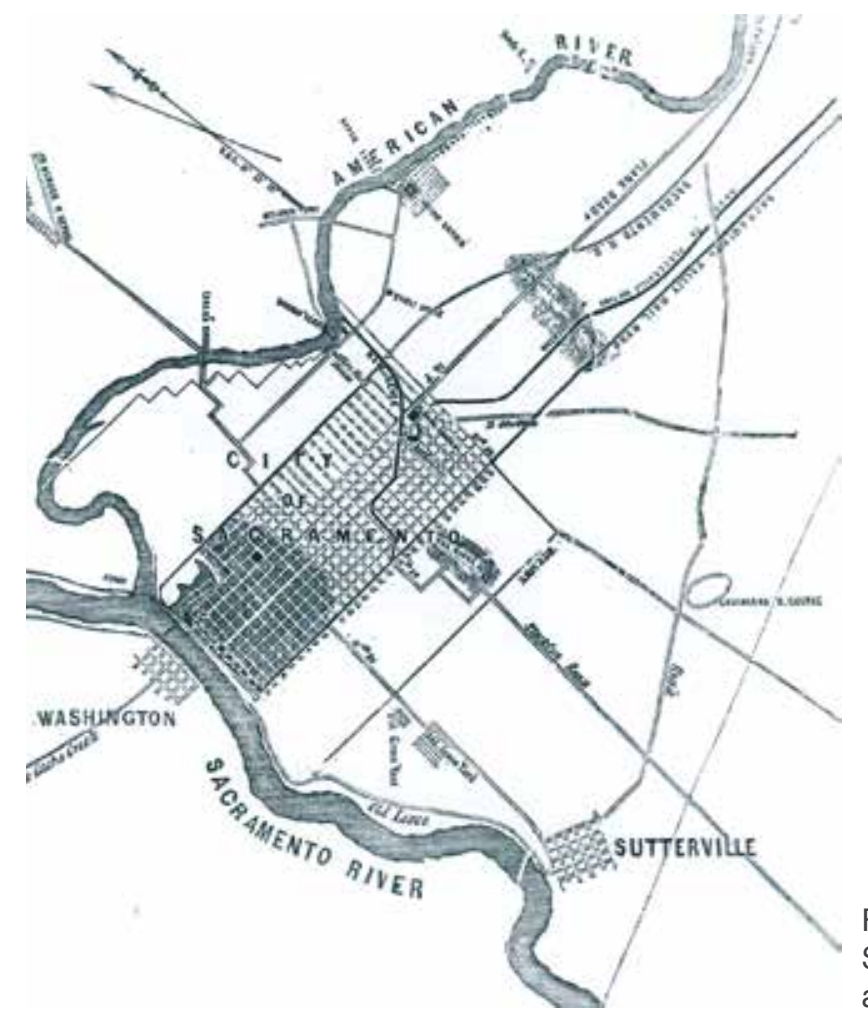

Figure 10. The City of

Sacramento with major roads and railway lines in 1855 .

These findings and interpretations are thought provoking if applied to Miami, because the "Magic City" regularly features as one of the most socially segregated agglomerations in the US. Its Gini coefficient, measuring social disparities, is high, corruption cases remain frequent, and the indicators of civic health are low. ${ }^{22}$ Though major riots have not occurred since the 1980s, unity is not the word that best characterizes Miami's political situation. The thesis that the city government's legitimacy could be raised and strengthened through the need of concerted action is 
hence alluring, and counterbalances the more frequent claim that Miami will not be able to solve its issues due to a culture of uncoordinated private action. The test could transcend into a societal way forward, but it might only be taken and passed, if the state of emergency is understood by the entire population, and consequences are supposed to be shared equally. A point that this chapter can only raise, but not analyze and discuss, is the appropriateness of the final result. As previously mentioned, a statewide flood control plan of remarkable cost and complexity has indeed helped to protect the Sacramento Valley and the wider area from further disasters, preventing the occasional creation of a vast inland sea in what are now densely populated areas. Critics however underline the ecological cost that this massive interference in an existing natural system has produced. The example underlines that the definition of resiliency, in opposition to resistance, is not as clear-cut as one would hope for. It also underlines the fact that natural preservation and human activities are not easy to reconcile, even in an age of raised ecological awareness.

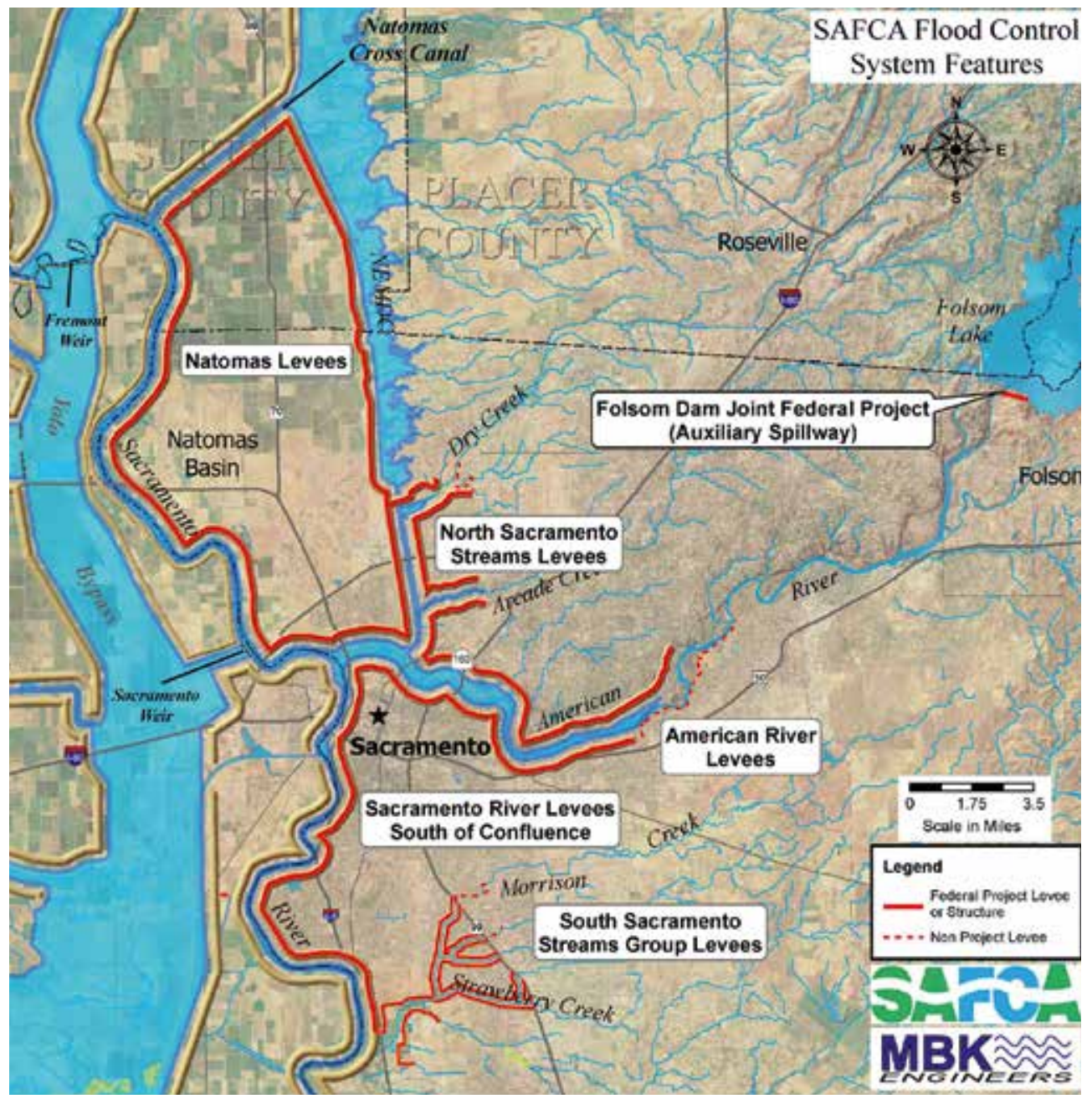

Figure 11. Map of the Sacramento Valley Flood Control System. The massive Yolo Bypass, to the west, has been created in order to channel overflowing water during the winter floods. 


\section{CONCLUSION}

Will Miami become a new Atlantis? The idea that the "Magic City" will not witness the turn of the next century is surprisingly wide spread. ${ }^{23}$ Pessimists cite many reasons, including the population's transience, the city's still relatively undiversified economy relying on tourism and speculative realestate investment, the particularity of the porous soil and the fact that its most valuable asset - arguably Miami Beach - is also its most threatened one. Be that as it may, it is not the aim of this paper to answer this question, even though the analysis of numerous case-studies, including the four presented in this paper, seems to document a strong natural resilience of human settlements to disaster.

What the authors intended to do, was to help put the current discussion into perspective, and to participate in the knitting of a flood control narrative that is based on historic experience, and detached from contemporary political and technocratic pressures that tend to direct ongoing remediation efforts into a deceptively pragmatic and problem-solving direction. That is because what is meant to reassure, can become ever more threatening, if the proposed solutions do not satisfy our perfectionist expectations and personal interests. Embracing change on the scale needed for the future of Miami is not an easy task, particularly if the risk is not equally distributed. The novelty in terms of risk is not its constant growth, but the linearity of this growth and its apparent predictability. ${ }^{24}$ The alleged clarity of the phenomenon of rising sea levels, captivating for our visual imagination, appears less abstract than the growing harm and financial loss created through a statistic of intensifying natural disasters. Awaiting the next hurricane seems to be psychologically less threatening than to prepare for the long-term effects of sea level rise. We do not know when the next hurricane will hit, but we do know that the sea levels will rise. Each major hurricane had a cost, but its impact on urban life and urban form was always limited in time, particularly for the elites who could build accordingly and leave the city until it resumed its major operating functions. Rising sea levels, for the reasons mentioned above, will change this paradigm for Miami and many other cities that do not have a culture of recurring flood disasters. The city's spatial development will be heavily affected, not only in terms of building codes, as in the case of hurricanes, but also in many other growth patterns.

In an attempt to situate this paper more specifically in the realm of the built environment, it is worthwhile mentioning that our position is not only one of observation. It is a byproduct of our own experience as design studio teachers who have over the last two years repeatedly invited architecture and urban design students to "find solutions for sea level rise." Often, these solutions cannot fully convince, the issue potentially being the expectation of "fully," one that architects tend to share with their engineering colleagues. It is a notion that seems to fit better into the above-mentioned category of 
"resistance," of full protection of the status quo, rather than "resilience." We hence ask ourselves if sea level rise may have been put in the wrong category, the one of technological challenges, while in reality having more in common with an issue like affordability that nobody would even dare to disconnect from its broader socio-economic, historic and political context. What consequences, if any, would such an understanding have for the work of the architect, urban designer or planner? How should the profession adjust in order to have a more powerful impact on the future of cities that are threatened by sea level rise?

\section{Notes}

1. John Abraham, "Sea Level Rise Is Accelerating; How Much It Costs Is up to Us," The Guardian (March 11, 2016), https://www.theguardian.com/environment/climateconsensus-97-per-cent/2016/mar/11/sea-level-rise-is-accelerating-how-much-it-costs-isup-to-us; Glenn Landers, US Army Corps of Engineers, Jacksonville District, "Seal Level Change and Long Range Water Resources Planning for Florida," (presentation, Miami-Dade "Sea Level Rise" Task Force Meeting, Miami, April 4, 2014).

2. FIU GIS Center, "Sea-Level Rise Toolbox," this website allows you to map sea level rise for specific locations according to the user's manual input, http://www.eyesontherise.org/ app/\#tab2.

3. Joey Flechas, "Flood Claim Denied for Restaurant Turned 'Basement' after Miami Beach Raised Street," Miami Herald (November 16, 2016), http://www.miamiherald.com/news/local/ community/miami-dade/miami-beach/article115264938.html.

4. Lance H. Gunderson, Craig Reece Allen, and C. S. Holling, Foundations of Ecological Resilience (Washington DC: Island Press, 2014).

5. Gregory S. Aldrete, Floods of the Tiber in Ancient Rome (Baltimore MD, USA: Johns Hopkins University Press, 2006), $10 \mathrm{ff}$.

6. Aldrete, Floods of the Tiber, 13-14.

7. Marcus Vitruvius Pollio, On Architecture, transl. Frank Stephen Granger (Cambridge MA, USA: Harvard University Press, 2014; $1^{\text {st }}$ transl., 1931).

8. Ibid., Book I, Chapter iv, 12.

9. John Keahey, Venice Against the Sea: A City Besieged (New York: Thomas Dunne Books/St. Martin's Press, 2002), 19.

10. Karl Appuhn, "Friend or Flood? The Dilemmas of Water Management in Early Modern Venice," in The Nature of Cities, ed. Andrew C. Isenberg (Rochester NY, USA: University of Rochester Press, 2006).

11. Ibid., 83.

12. Ibid., 80.

13. Ibid., 86.

14. Fred Daspit, Louisiana Architecture, 1714-1820 (Lafayette LA, USA: Center for Louisiana Studies, University of Louisiana at Lafayette, 2004); Federal Emergency Management Agency (FEMA), The History of Building Elevation in New Orleans (Washington DC, December 2012), https://www.fema.gov/media-library-data/20130726-1919-25045-5921/ cno_history_bldg_elev_042313.pdf.

15. Sherry Johnson, Climate and Catastrophe in Cuba and the Atlantic World in the Age of Revolution (Chapel Hill NC, USA: The University of North Carolina Press, 2011), 8ff. 16. FEMA, 6.

17. Andrew C. Isenberg, "Banking on Sacramento," in The Nature of Cities (Rochester NY, USA: University of Rochester Press, 2006), 104.

18. Todd Holmes, "Rivers of Gold, Valley of Conquest," in River City and Valley Life, eds. Christopher Castaneda and Lee Simpson (Pittsburgh PA, USA: University of Pittsburgh Press, 2013), 122 
19. Isenberg, "Banking on Sacramento," 117.

20. Robert Kelley, Battling the Inland Sea (Berkeley CA, USA: University of California Press, 1989), 15.

21. Ibid, 319-338. In the final chapter of his book, Kelley analyzes the relevance of the valley's special environmental conditions for the political culture in California.

22. Sarah Ponczek and Wei Lu, "The 10 Most Unequal Cities in America," Bloomberg.com (October 5, 2016), https://www.bloomberg.com/news/articles/2016-10-05/miami-is-thenewly-crowned-most-unequal-city-in-the-u-s; National Conference on Citizenship, A Tale of Two Cities - Civic Health in Miami and Minneapolis-St. Paul, (Miami: John S. and James L. Knight Foundation, Report, 2010).

23. Jeff Goodell, "Miami: How Rising Sea Levels Endanger South Florida," Rolling Stone (June 20, 2013), http://www.rollingstone.com/politics/news/why-the-city-of-miami-is-doomedto-drown-20130620.

24. Though surpassing the scope of this paper, the topic of sea level rise could also be analyzed in the context of the writings about the "risk society" by authors like Anthony Giddens, Ulrich Beck and others.

\section{References}

Aerts, Jeroen C. J. H. Climate Adaptation and Flood Risk in Coastal Cities Abingdon. Oxon, UK; New York: Earthscan, 2012.

Aldrete, Gregory S. Floods of the Tiber in Ancient Rome. Baltimore MD, USA: Johns Hopkins University Press, 2007.

Blake, Nelson Manfred. Land into Water-Water into Land: A History of Water Management in Florida. Tallahassee FL, USA: University Presses of Florida, 1980.

Castaneda, Christopher James, and Lee M. A. Simpson. River City and Valley Life: An Environmental History of the Sacramento Region. Pittsburgh PA, USA: University of Pittsburgh Press, 2013.

Curtis, Daniel R. Coping with Crisis the Resilience and Vulnerability of Pre-Industrial Settlements. Farnham, UK: Ashgate Publishing Ltd, 2014.

Daspit, Fred. Louisiana Architecture, 1714-1830. Lafayette LA, USA: Center for Louisiana Studies, University of Southwestern Louisiana, 1996.

Dickson, Eric. Urban Risk Assessments an Approach for Understanding Disaster and Climate Risk in Cities. Edited by Judy L. Baker, Daniel Hoornweg and World Bank Content Provider. Washington DC: World Bank Publications, 2012.

Federal Emergency Management Agency (FEMA). The History of Building Elevation in New Orleans. Washington DC: Federal Emergency Management Agency, 2012.

Fletcher, Caroline. The Science of Saving Venice. Edited by Jane da Mosto. Turin, It.: Umberto Allemandi, 2004.

- -, and T. Spencer. Flooding and Environmental Challenges for Venice and

Its Lagoon: State of Knowledge. Cambridge, UK: Cambridge University Press, 2005.

Gil-Guirado, Salvador, José-Antonio Espín-Sánchez, and María Rosario Prieto. "Can We Learn from the Past? Four Hundred Years of Changes in Adaptation to Floods and Droughts. Measuring the Vulnerability in Two Hispanic Cities." Climatic Change 139, no. 2 (2016): 183-200.

Glaser, Rü, Dirk Riemann, Johannes Schönbein, Mariano Barriendos, Rudolf Brázdil, Chiara Bertolin, Dario Camuffo, et al. "The Variability of European Floods since AD 1500." Climatic Change 101, no. 1-2 (2010): 235-256.

Gunderson, Lance H., Craig Reece Allen, and C. S. Holling. Foundations of Ecological Resilience. Washington DC: Island Press, 2014.

Huitema, Dave, and Stefania Munaretto. "Adaptive Co-management in the Venice Lagoon? an Analysis of Current Water and Environmental Management Practices and Prospects for Change." Ecology and Society 17, no. 2 (2012): 19.

Isenberg, Andrew C. The Nature of Cities. Rochester NY, USA: University of Rochester Press, 2006.

James, L. A., and Michael B. Singer. "Development of the Lower Sacramento Valley FloodControl System: Historical Perspective." Natural Hazards Review 9, n.3 (2008): 125-135. 
Jha, Abhas K. Cities and Flooding: A Guide to Integrated Urban Flood Risk Management for the 21st Century. Edited by Robin Bloch and Jessica Lamond. Washington DC: World Bank Publications, 2012.

Johnson, Sherry. Climate and Catastrophe in Cuba and the Atlantic World in the Age of Revolution. Chapel Hill NC, USA: The University of North Carolina Press, 2011.

Keahey, John. Venice Against the Sea: A City Besieged. New York: Thomas Dunne Books/St. Martin's Press, 2002.

Kelley, Robert Lloyd. Battling the Inland Sea: American Political Culture, Public Policy, and the Sacramento Valley, 1850-1986. Berkeley CA, USA: University of California Press, 1989.

Lasserre, Pierre, and Angelo Marzollo. The Venice Lagoon Ecosystem: Inputs and Interactions between Land and Sea. Paris and New York: Parthenon Pub. Group, 1999. Lorenzetti, Giulio. Venice and its Lagoon: Historical-Artistic Guide. Trieste, It.: Lint, 1975.

Miller, E. Willard, and Ruby M. Miller. Natural Disasters: Floods - A Reference Handbook. Santa Barbara CA, USA: ABC-CLIO, 2000.

O’Malley, Anthony, and Coby Crowl. "Higher Ground." Civil Engineering 68, no. 9 (1998): 65-67.

Tarazona, Marcela, Federica Chiappe, and Chris Hearle. Understanding the Patterns of Climate-Resilient Development: A Literature Review. Final Report. Oxford, UK: Oxford Policy Management, June 2014.

URS Group. "The History of Building Elevation in New Orleans.” Washington DC: Federal Emergency Management Agency, 2012.

Van de Ven, G. P., and Karel Mulder. "Man-Made Lowlands: History of Water Management and Land Reclamation in the Netherlands." Technology and culture 37, no. 1, (1996): 210.

Van Meerten, H. "Controlling the Floods of the Mississippi." Journal of the Franklin Institute 157, no. 5 (1904): 381-387.

Viganò, Paola. "Extreme Cities and Bad Places." International Journal of Disaster Risk Science 3, n. 1 (2012): 3-10.

Vitruvius, Marcus Pollio. On Architecture. Translated by Frank Stephen Granger. Cambridge MA, USA: Harvard University Press, 2014; $1^{\text {st }}$ translation, 1931. 


\section{Acknowledgments}

We both worked in close collaboration on this paper, regarding the concept as much as the actual writing. For the Research part, Victor Deupi concentrated on Ancient Rome and New Orleans, while Eric Firley on Venice and Sacramento.

\section{Credits}

Figure 1: public domain, Flickr, photo by miamibrickell.

Figure 2: public domain, https://robertscribbler.com/tag/miami-sea-level-rise/.

Figures 4, 6 and 8: public domain.

Figure 5: photo credit to Gregory S. Aldrete.

Figures 7 and 10: images found in the book The Nature of Cities.

Figure 9: image found in the document The History of Building Elevation in New Orleans.

Eric Firley is an Assistant Professor at the School of Architecture, University of Miami, since January 2011. He trained as an architect and urban designer at the EPFL Lausanne, the Bauhaus University in Weimar and the London School of Economics. After his studies, he worked for several years in the real-estate sector and for design practices in Paris and London. Between 2007 and 2010, he concentrated full-time on the research for the selfinitiated Urban Handbook Series, published by John Wiley \& Sons.

E-mail: efirley@miami.edu

Victor Deupi is a Lecturer at the School of Architecture, University of Miami, where he teaches history and theory, design and representation. The principal focus of his research is on the art and architecture of the Early Modern Ibero-American world, and mid-twentiethcentury Cuba. His book Architectural Temperance: Spain and Rome, 1700-1759 was published by Routledge in 2015, and he is currently editing a book on Transformations in Classical Architecture that is being published by Oscar Riera Ojeda Publishers, 2017. E-mail:vdeupi@miami.edu 